\title{
Google trend analysis of climatic zone based Indian severe seasonal sensitive population
}

\author{
Jai Chand Patel, Pankaj Khurana, Yogendra Kumar Sharma, Bhuvnesh Kumar and Ragumani Sugadev* (D)
}

\begin{abstract}
Background: Our earlier Google Trend (GT) Analytics study reported that the worldwide human population severely subject to four seasonal (sensitive) comorbid lifestyle diseases (SCLD) such as asthma, obesity, hypertension and fibrosis. The human population subject to seasonal variability in these four diseases activity referred as "severe seasonal sensitive population". In India, the estimated burden of these four seasonal diseases is more than 350 million as on the year 2018. It is a growing crisis for India with a projected disease burden of 500 million in the year 2025. This study was aimed to decipher the genuine SCLD seasonal trends in the entire Indian population using GT and validate these trends in Indian climatic zones.

Methods: GT is used to study the temporal trends in web search using weekly Relative Search Volume (RSV) for the period 2004 to 2017. The relative search volume (RSV) of the four-severe seasonal comorbid diseases namely Asthma, Hypertension, Obesity and Fibrosis were collected with and without obesity as the reference. The RSV were collected using the GT selection options as (i) Whole India (ii) Jammu and Kashmir (Cold zone) (iii) Rajasthan (Hot and Dry zone) (iii) West Bengal (Hot and Humid zone) and (iv) Uttar Pradesh state (Composite zone). The time series analysis was carried out to find seasonal patterns, comorbidity, trends and periodicity in the entire India and four of its states (zones).

Results: Our analysis of entire India (2004-2017) revealed high significant seasonal patterns and comorbidity in all the four diseases of SCLD. The positive tau values indicated strong positive seasonal trends in the SCLD throughout the period (Table). The auto correlation analysis revealed that these diseases were subjected to 3, 4 and 6 months period seasonal variations. Similar seasonal patterns and trends were also observed in all the four Indian temperature zones. Overall study indicated that SCLD seasonal search patterns and trends are highly conserved in India even in drastic Indian climatic zones.

(Continued on next page)
\end{abstract}

\footnotetext{
* Correspondence: ragusugadev@gmail.com
}

Defence Institute of Physiology and Allied Sciences, Defence Research and

Development Organization, Lucknow Road, Timarpur, Delhi, India

C C The Author(s). 2020 Open Access This article is licensed under a Creative Commons Attribution 4.0 International License, which permits use, sharing, adaptation, distribution and reproduction in any medium or format, as long as you give appropriate credit to the original author(s) and the source, provide a link to the Creative Commons licence, and indicate if changes were made. The images or other third party material in this article are included in the article's Creative Commons licence, unless indicated otherwise in a credit line to the material. If material is not included in the article's Creative Commons licence and your intended use is not permitted by statutory regulation or exceeds the permitted use, you will need to obtain permission directly from the copyright holder. To view a copy of this licence, visit http://creativecommons.org/licenses/by/4.0/ The Creative Commons Public Domain Dedication waiver (http://creativecommons.org/publicdomain/zero/1.0/) applies to the data made available in this article, unless otherwise stated in a credit line to the data. 


\begin{abstract}
(Continued from previous page)
Conclusions: The clinical outcome arise out of these observations could be of immense significance in handling the major chronic life style diseases asthma, hypertension, obesity and fibrosis. The possible strong comorbid relationship among asthma, hypertension, obesity and fibrosis may be useful to segregate Indian seasonal sensitive population. In disease activity-based chronotherapy, the search interest of segment of the population with access to Internet may be used as an indicator for public health sectors in the early detection of SCLD from a specific country or a region. As this disease population could be highly subject to the adverse effect of seasons in addition to life style and other environmental factors. Our study necessitates that these Indian populations need special attention from the Indian health care sectors.
\end{abstract}

Keywords: Google trends, Seasonal sensitive population, Comorbid

\section{Background}

The main environmental provocation from ambient climate, temperature change, elevated levels of air pollution impact on vulnerable individuals contribute to adverse change in their behavioural and physiological responses. In the historical era, the seasonal variation in non-communicable diseases was well recognized in ayurvedic and homeopathic medicines [1-3]. In the modern era, scant attention is paid on the seasonal perspective based critical examination of the non-communicable diseases due to human population across the globe has gradually extended with our ability (from heating to cooling) to achieve optimal habitat and work-place temperature control. In contrary, number of contemporary studies confirmed that enormous number of human populations across the globe influenced by the environment changes in particular to season variations with predominance winter peaks.

From the broader, beyond geographical location, the extent of seasonality in non-communicable diseases of a specific area is indeed attenuated or prevented by the micro climate of that region. There were several studies observed inconsistencies in both observe and report of seasonal variations in non-communicable diseases of a region-specific population. To reduce the interference of environmental provocations on genuine season effect, the locations studied should be geographically widespread where conventional data collection may be challenging and resource intensive. One tool Google Trends allows users to freely access three billion daily Google Search searches and provides data on widespread geospatial and temporal patterns in search volumes for user-specified terms [4-7].

Using Google Trend analytics, in seasonal perspective, our earlier study provided an indirect evidence of four comorbid seasonally sensitive diseases hypertension, asthma, fibrosis and obesity severely affect the human population worldwide in myriad of the above said environment together with ethnic variations named as "seasonal (sensitive) comorbid lifestyle diseases (SCLD)" [8].
The predicted seasonal comorbid association among asthma, hypertension and obesity is highly supported by clinical evidences [9-14]. Even though fibrotic diseases strongly associate with season, their seasonal comorbid association with obesity, hypertension, and asthma is poorly evaluated [15]. Our study predicted reverse in the comorbid seasonal search trends of SCLD between USA (Northern hemisphere) and New Zealand (Southern hemisphere).

Several clinical studies on Indian population reported many folds increase in the prevalence of the life style disorders [16-19]. For example the prevalence of obesity in India increased drastically to the alarming level of 30 to $40 \%$ in tune with the world population $[20,21]$. The present study utilized GT from India to estimate the seasonality in these diseases especially SCLD and their comorbidity. In India, there are multiple factors could attenuate the seasonality in SCLD. The major factors are temperature and rainfall of the geographical locations, and the periods of searches (year, month and week) [2227]. India has been divided into four major main climatic regions based on temperature and rainfall namely hot \& dry, cold, composite and hot \& humid [28]. Within diverse climatic regions, densely populated urban areas and distinct geographical features have potentially modulated both the overall climatic conditions and mean temperatures of those regions. In addition, in each climatic regions the Indian population exhibits diversities in social, culture, linguistics and in their genetic profiles $[29,30]$.

The present study tried to decipher the genuine seasonal effect in SCLD of whole Indian population with the following objective (i) to estimate the seasonal trends in SCLD and their comorbidity using GT for the period 2004-2017. The main outcome of the analysis includes: (a) highly significant seasonal search trends and comorbidity were noticed in SCLD. The similar significant seasonal trends were also validated in the four climatic zones of India. The significant seasonal search patterns in entire India and its climatic zones indicate that SCLD are growing crisis for India. 


\section{Methods}

Selection criteria of Indian states for GT based on climatic zones

India is divided into 28 states on the basis of linguistics and culture [31]. In India, there are five climatic zones viz. cold, hot and dry, hot and humid, moderate and composite. Most of the Indian states belong to more than one climatic zone with few states lie in the single climatic zone. Indira et al., 2014 characterized and defined the boundary of the five climatic zones from the 15 years of per day weather reports from five weather stations (Srinagar, Jodhpur, Kolkata, Bangalore and New Delhi) belong to the five climatic zones [28]. The selection criteria of Indian states based on the characteristics of different climatic zones as follows (i) Cold climate zone with low solar radiation, in summer the maximum ambient temperature of $20-30{ }^{\circ} \mathrm{C}$ during the day and $0-$ $10^{\circ} \mathrm{C}$ at night, in winter the values are between 5 and $25^{\circ} \mathrm{C}$ during the day and $0-10 \mathrm{C}$ at night, low relative humidity (25-40\%) encompasses the Jammu and Kashmir state (ii) Hot \& dry zone with high solar radiation 800-900 W.m2, in summer the maximum ambient temperature of $40-45^{\circ} \mathrm{C}$ during the day and $20-30{ }^{\circ} \mathrm{C}$ at night, in winter the values are between 5 and $25^{\circ} \mathrm{C}$ during the day and $0-10{ }^{\circ} \mathrm{C}$ at night, low relative humidity $(25-40 \%)$ and low rainfall $<500 \mathrm{~mm}$ encompasses the Rajasthan state (excluding the eastern and southern fringes). (iii) Hot and humid climate zone with intense solar radiation, in summer the maximum ambient temperature of $30-35^{\circ} \mathrm{C}$ during the day and $25-30{ }^{\circ} \mathrm{C}$ at night, in winter the values are between 25 and $30^{\circ} \mathrm{C}$ during the day and $20-25^{\circ} \mathrm{C}$ at night, low relative humidity (70-90\%) encompasses the West Bengal State (iv) The Composite climate zone with high solar radiation in summer and low diffusion in monsoon, in summer the maximum ambient temperature of $10-25^{\circ} \mathrm{C}$ during the day and $4-10{ }^{\circ} \mathrm{C}$ at night, low relative humidity (20$25 \%$ ) in summer and reaches up to $55-95 \%$ in monsoon encompasses the Uttar Pradesh State (v) The moderate climate zone covering hilly areas and high plateau regions of India omitted from the analysis as it does not encompass any specific state as in the case of other climate zones.

\section{Google trend data collection}

GT is used to study the temporal trends in web search using monthly and weekly Relative Search Volume (RSV). The relative search volume (RSV) of the foursevere seasonal comorbid diseases namely Asthma, Hypertension, Obesity and Fibrosis were collected with and without obesity as the reference. In the query, as a default option "all categories" and "all types of web search" were used. The RSV were collected using the GT selection options as (i) Whole India (ii) Jammu and
Kashmir (Cold zone) (iii) Rajasthan (Hot and dry zone) (iii) West Bengal (Hot and humid zone) and (iv) Uttar Pradesh (Composite zone).

\section{Data analysis}

Data processing and statistical analysis were carried out using 'trend' and 'stats' packages in $\mathrm{R}$ version 3.5.0 [32, 33]. The Mann-Kendall and seasonal Mann-Kendall trend tests were used to detect overall trends significantly larger than the variance in the data for the SCLD search terms $(\alpha=0.05)$. To determine the significant seasonal components, an exponential smoothing state space model with Box-Cox transformation, trend, and seasonal components (TBATS) were fitted to the data using 'forecast' package [34]. Further, autocorrelation was performed to extract the cyclic patterns present in the data using 'stats'.

\section{Results}

Worldwide, four life style disorders (hypertension, obesity, asthma and fibrosis) were recognized to have strong seasonal linkage. Furthermore, the complex comorbid connections among them demonstrated that such connections can be highly time varying public problem. No definite consensus currently exists to study the dynamic changes. Our earlier study revealed that such dynamic connections and change in their co-occurrence (comorbid) due to external stimuli (seasons) significantly associated with the time varying user internet search patterns [8]. To take this idea further, in our study we aim to test the hypothesis in a country population subject to moderate seasonal changes such as Indian population (average temperature varies from $25^{\circ} \mathrm{C}$ to $45^{\circ} \mathrm{C}$ ). The climate of India comprises a wide range of weather conditions across a vast geographic scale and varied topography, making our generalisations problematic. In this context, we therefore proposed an evaluation of model scenarios, with temperature as variable. The temperature dependent data-driven model scenarios account for the four major climatic zones of India were individually analysed.

\section{Entire country weekly GT analysis without bench mark} Without benchmark, the week wise and month wise varying RSV for the SCLD were analysed for seasonal trend in the period 2004 to 2017. The seasonal MannKendall showed no seasonal trends in SCLD in both monthly as well as weekly datasets. The RSV plot showed high noise levels in the weekly GT data sets (Fig. 1). To reduce the noise levels, the weekly datasets were subjected to 4 weeks moving average to derive monthly datasets for each disease. Surprisingly, this approach improved the data quality considerably and resulted highly significant seasonal trends in all the four 


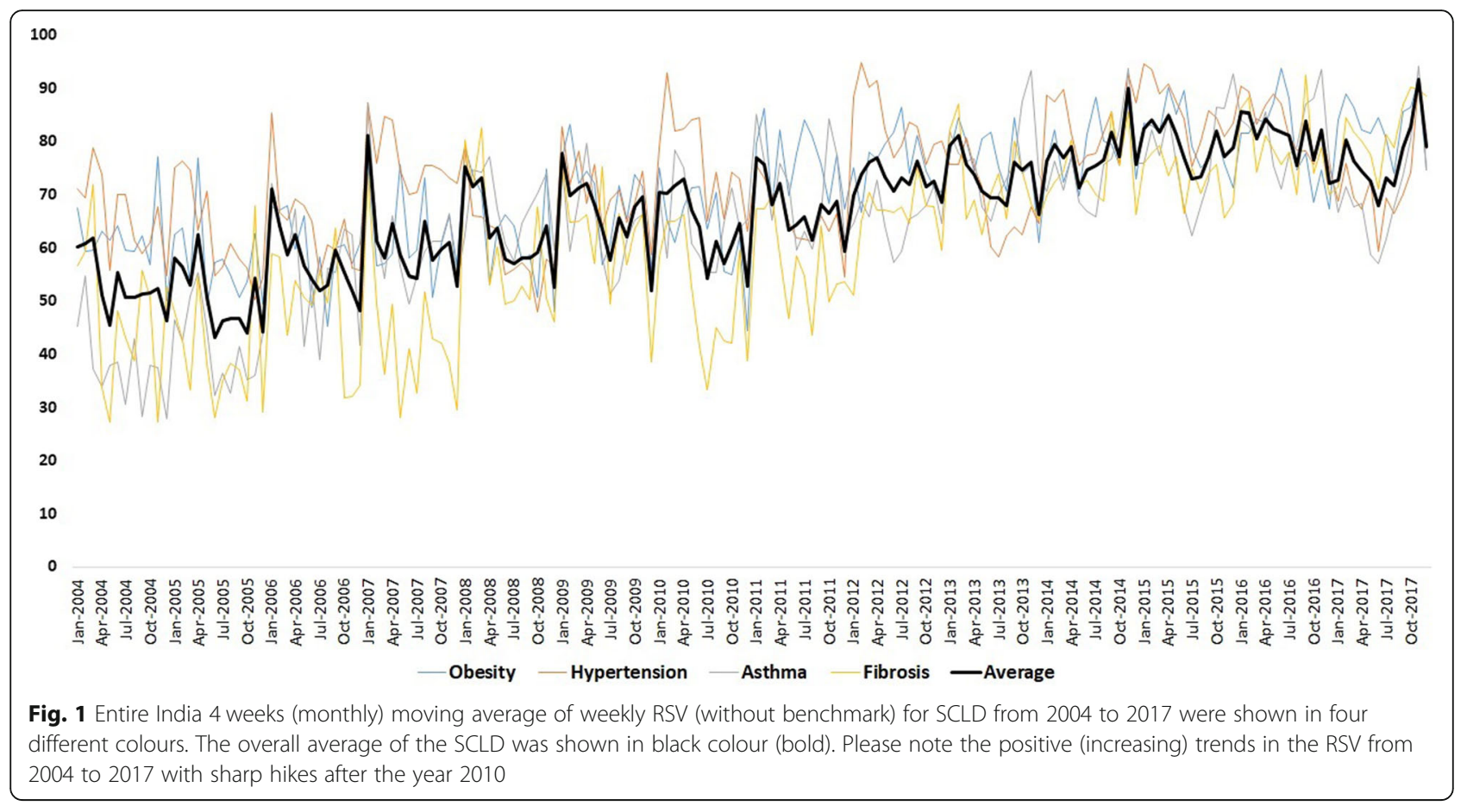

diseases of SCLD (Table 1). The positive tau values indicated strong positive trends search patterns in the SCLD. The RSV average of the four SCLD exposed the quantum jumps in the trends after the year 2010. Furthermore, the seasonal decomposition of the GT also revealed 4 and 6 months periodicity especially in asthma, obesity and fibrosis (Fig. 2). The autocorrelation analysis also revealed seasonal periodicity in the SCLD except hypertension (Fig. 3).

\section{Entire country monthly GT analysis with benchmark}

With benchmark, the monthly RSV from entire India was used to study the comorbid trends among SCLD. The seasonal Mann-Kendall captured significant seasonal comorbid trends in the four SCLD for the period 2004 to 2017. To reduce the noise levels and capture comorbid patterns, the monthly RSV of SCLD were subjected to seasonal moving average of window size 4 . The window size was decided on the basis of GT weekly periodicity analysis (Table 2). All the four diseases seasonal comorbid patterns were well maintained in the entire period 2004 to 2017 (Fig. 4). Particularly, among SCLD the seasonal comorbid patterns between asthma and obesity were highly matched.

\section{Zone wise GT analysis}

Without benchmark, the zone wise weekly varying RSV of the SCLD were analysed for seasonal trend in the period 2004 to 2017 . Before the analysis, the weekly datasets without benchmark were subjected to 4 weeks (monthly) moving average. The seasonal Mann-Kendall and Mann-Kendall captured statistically significant seasonal patterns and trends respectively in SCLD from different zones (Table 3). The zone wise seasonal trends of SCLD were highly comparable with that of entire India. The zone wise GT analysis with benchmark was omitted due to the weak RSV (Table 4).

\section{Discussion}

The present study successfully addressed all the objectives and revealed the following major outcomes.

Table 1 Time series analysis of entire India 4 weeks (monthly) moving average of weekly RSV (without benchmark) for SCLD from 2004 to 2017

\begin{tabular}{|c|c|c|c|c|c|c|c|c|c|c|c|c|}
\hline & \multirow[t]{2}{*}{ Mean } & \multirow[t]{2}{*}{ Stdev } & \multicolumn{4}{|c|}{ Seasonal Mann-Kendall } & \multicolumn{5}{|c|}{ Mann-Kendall } & \multirow{2}{*}{$\begin{array}{l}\text { Seasonal } \\
\text { periodicity }\end{array}$} \\
\hline & & & z & $\boldsymbol{p}$-value & $S$ & vars & z & S & vars & tau & $\boldsymbol{p}$-value & \\
\hline Obesity & 70.77 & 11.15 & 10.24 & $<0.01$ & 649 & 3999 & 9.83 & 7174 & $531,445.3$ & 0.51 & $<0.01$ & 3,4 \\
\hline Asthma & 64.99 & 14.66 & 10.92 & $<0.01$ & 692 & 4002 & 10.19 & 7435 & 531,463 & 0.53 & $<0.01$ & $3,4,6$ \\
\hline Hypertension & 72.78 & 10.84 & 6.83 & $<0.01$ & 433 & 3999 & 5.84 & 4261 & 531,459 & 0.30 & $<0.01$ & - \\
\hline Fibrosis & 61.04 & 16.18 & 11.43 & $<0.01$ & 724 & 4000 & 11.03 & 8044 & 531,460 & 0.57 & $<0.01$ & 4,6 \\
\hline
\end{tabular}

stdev Standard deviation, $z$ Mann-Kendall statistics, S (Positive differences- Negative differences), varS Variance of S 

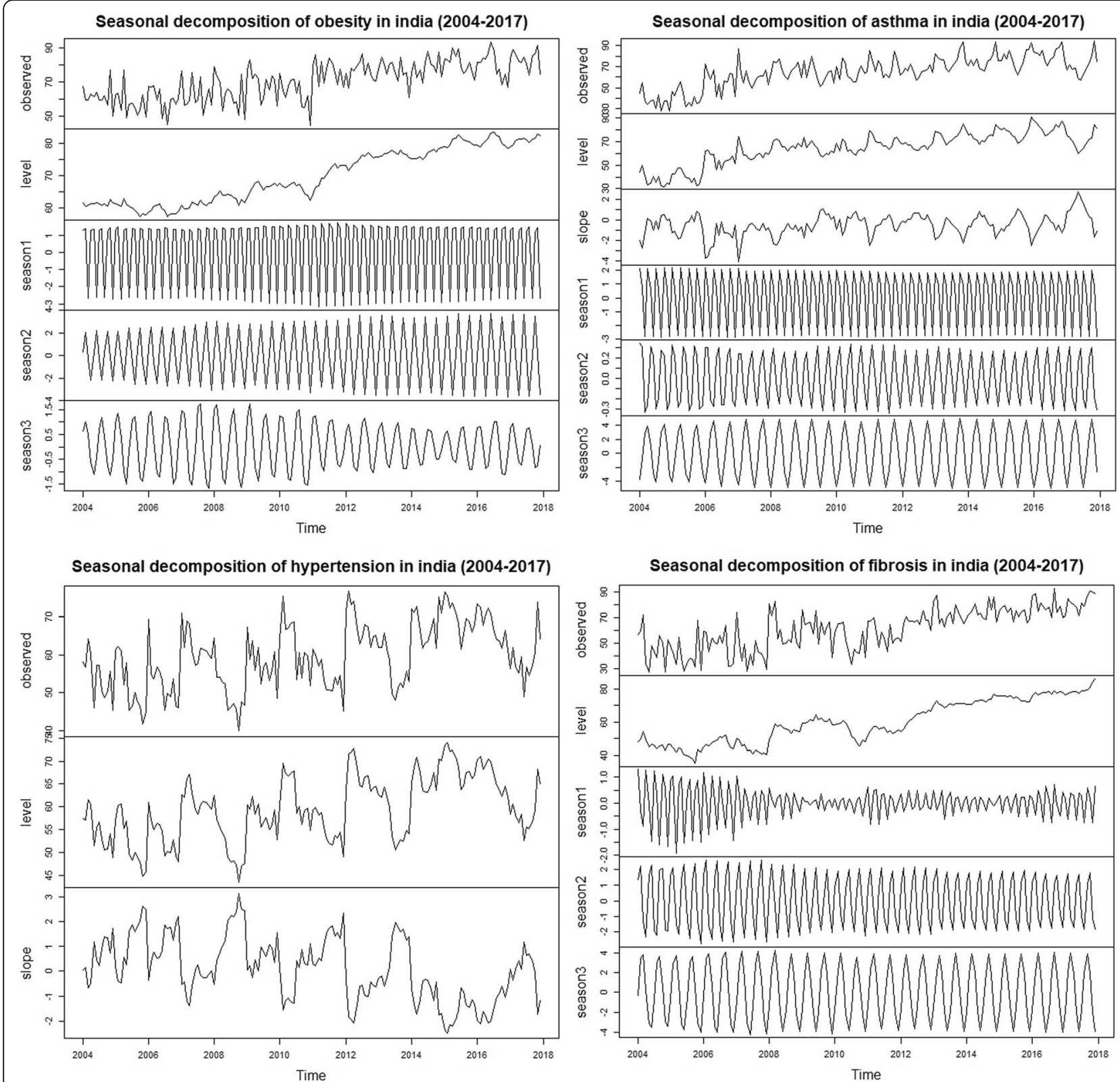

Fig. 2 Seasonal and trend decomposition using TBATS for the SCLD for the weekly average (4 weeks) RSV from 2004 to 2017 without benchmark disease. Four weeks averaged weekly data were displayed for the SCLD in the top panels as observed (trend), level, slope and seasonal components 1, 2, and 3. Please note that strong seasonal patterns in all the SCLD except hypertension viz. 3 months (season 1), 4 months (season 2) and 6 months (season 3)

\section{SCLD is a growing crisis for India}

In India, according to I-Cube Internet user survey report 2018 more than 566 million have access to the Internet, accounting for $40 \%$ of the total population (https:// imrbint.com/images/common/ICUBE\%E2\%84\%A2_201 9_Highlights.pdf). Such a large population of web users should provide reliable data for the SCLD surveillance in India. First time, our study revealed the highly significant seasonal patterns as well as more positive seasonal trends of SCLD in the internet search patterns from
India. Furthermore, the internet weekly relative search volume (RSV) was also hiked after 2010 for SCLD. Similar positive trends were also noticed in the zone wise analysis. Several clinical studies of SCLD except fibrosis also reported the significant hike in the patient volumes after 2010 in India [25, 35, 36]. But clinical studies support our predicted seasonal comorbid trend among SCLD in overall Indian population was highly limited or negligible. Worryingly, the estimated diseases burden for the year 2017 was 207 million for hypertension, 135 for 


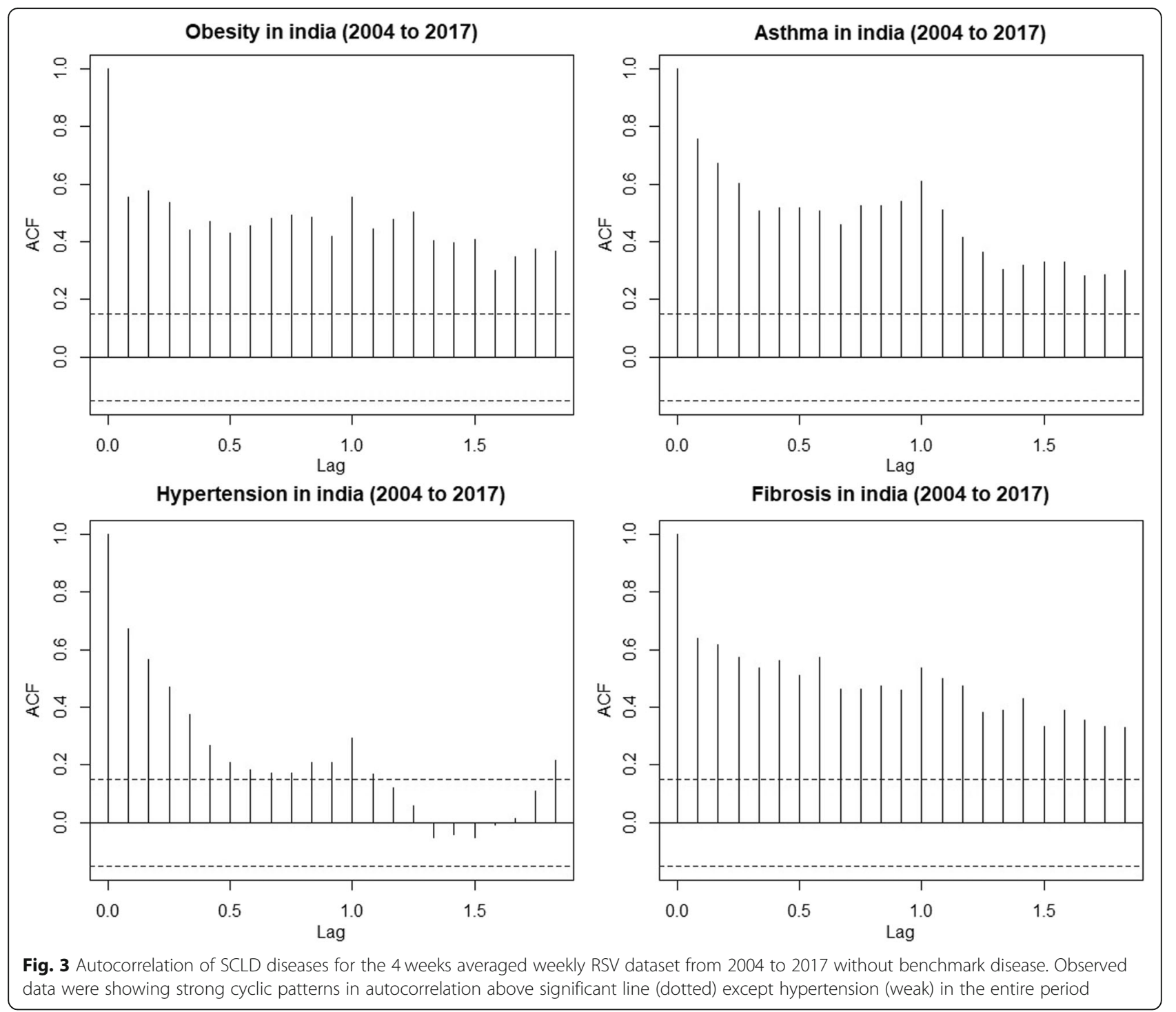

Table 2 Time series analysis of entire India seasonal (4 months) moving average of weekly RSV (with benchmark) for SCLD from 2004 to 2017

\begin{tabular}{lccccccc}
\hline & Mean & Stdev & \multicolumn{5}{c}{ Seasonal Mann-Kendall } \\
\cline { 3 - 8 } & & & $\mathrm{z}$ & $\mathrm{S}$ & varS & $\boldsymbol{p}$-value \\
\hline India & & & & & & \\
Obesity & 19.63 & 12.36 & -15.69 & -989 & 3961 & $<0.001$ \\
Asthma & 22.55 & 13.46 & -13.35 & -839 & 3935 & $<0.001$ \\
Hypertension & 30.53 & 24.07 & -15.80 & -996 & 3962 & $<0.001$ \\
Fibrosis & 8.57 & 6.96 & -14.15 & -876 & 3822 & $<0.001$ \\
\hline stdev Standard deviation, $\boldsymbol{z}$ Mann-Kendall statistics, S S (Positive differences- \\
Negative differences), varS Variance of S
\end{tabular}

obesity, 37.9 for asthma and no registry for fibrosis to cross more than 500 million in the year 2022 [36-38]. Overall, our findings indicated that SCLD is a growing major crisis of health system in India. The seasonal severity and comorbidity could be addressed explicitly for the effective control and to take preventive measures of SCLD.

\section{Implication of GT in SCLD Chronotherapy}

Chronotherapy is the synchronizing of drug concentrations to rhythms in disease activity, increasing efficacy as well as reducing adverse effects a major consideration to improve modern personalized medicine [39]. The rhythms in disease activity orchestrate either in terms of external clock time or internal circadian biological time $[40,41]$. Clinical studies indicated that not only the external (to the local time) but also the internal circadian rhythms of human depend on season [42]. But the adverse effect of seasons 


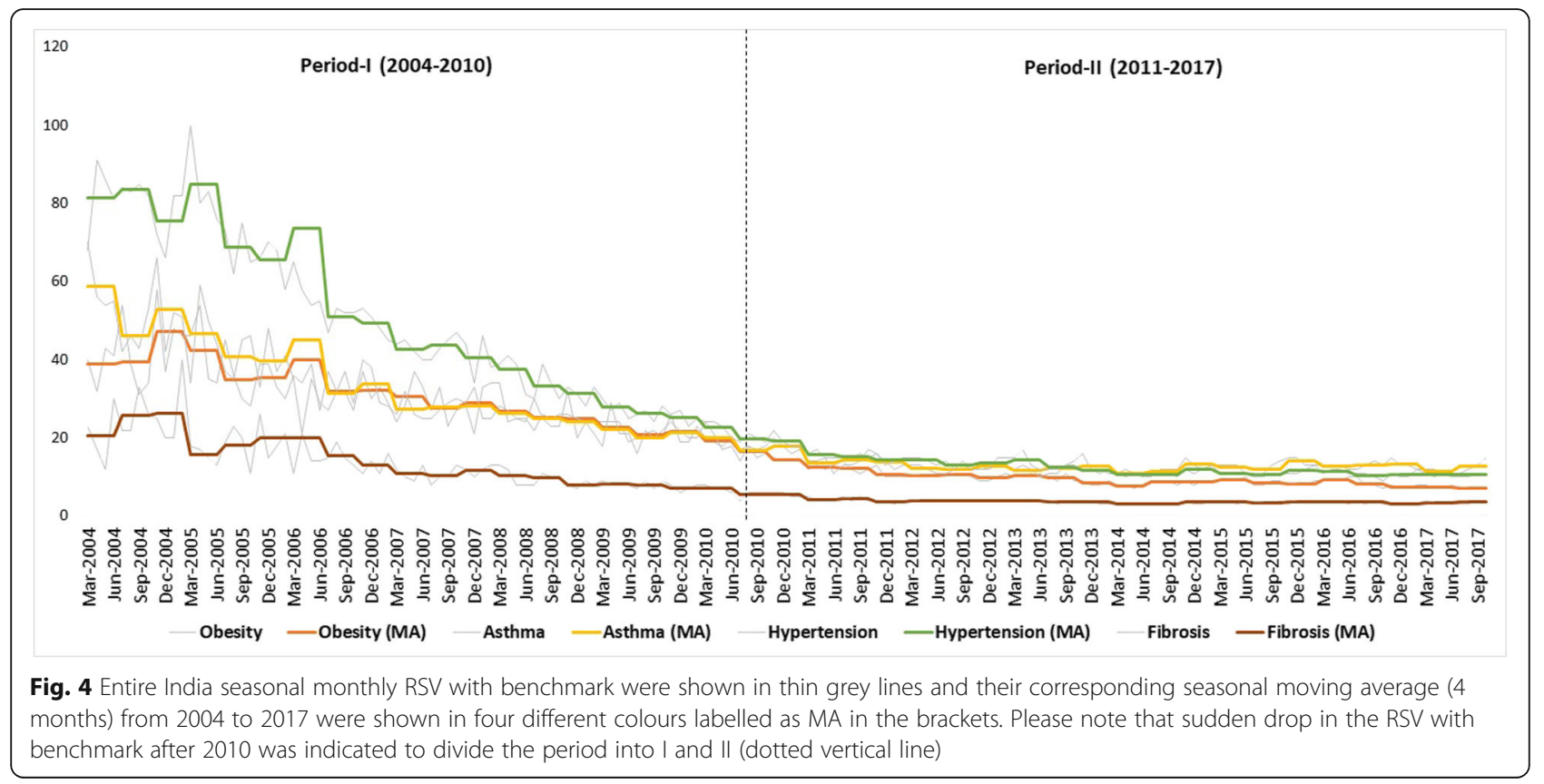

Table 3 Time series analysis of zone wise 4 weeks (monthly) moving average of weekly RSV (without benchmark) for SCLD from 2004 to 2017

\begin{tabular}{|c|c|c|c|c|c|c|c|c|c|c|c|}
\hline & \multirow[t]{2}{*}{ Mean } & \multirow[t]{2}{*}{ Stdev } & \multicolumn{5}{|c|}{ Mann-Kendall } & \multicolumn{4}{|c|}{ Seasonal Mann-Kendall } \\
\hline & & & z & S & varS & tau & $\boldsymbol{p}$-value & z & $S$ & varS & $\boldsymbol{p}$-value \\
\hline \multicolumn{12}{|l|}{ Jammu Kashmir } \\
\hline Obesity & 7.80 & 13.72 & 9.99 & 6137.00 & $377,519.70$ & 0.58 & $<0.01$ & 9.87 & 522.00 & 2787.33 & $<0.01$ \\
\hline Asthma & 7.72 & 13.49 & 10.10 & 6103.00 & $364,707.70$ & 0.59 & $<0.01$ & 9.75 & 505.00 & 2674.33 & $<0.01$ \\
\hline Hypertension & 13.52 & 20.34 & 12.39 & 8079.00 & $425,347.00$ & 0.71 & $<0.01$ & 12.19 & 685.00 & 3149.67 & $<0.01$ \\
\hline Fibrosis & 4.65 & 11.27 & 7.60 & 3794.00 & $248,961.30$ & 0.46 & $<0.01$ & 7.51 & 320.00 & 1802.00 & $<0.01$ \\
\hline \multicolumn{12}{|l|}{ Rajasthan } \\
\hline Obesity & 22.71 & 18.92 & 10.44 & 7526.00 & $519,578.00$ & 0.56 & $<0.01$ & 10.15 & 632.00 & 3868.00 & $<0.01$ \\
\hline Asthma & 26.31 & 20.08 & 10.47 & 7584.00 & $524,639.30$ & 0.56 & $<0.01$ & 10.20 & 640.00 & 3924.00 & $<0.01$ \\
\hline Hypertension & 30.44 & 23.10 & 11.10 & 8056.00 & $526,928.00$ & 0.59 & $<0.01$ & 11.27 & 705.00 & 3901.67 & $<0.01$ \\
\hline Fibrosis & 13.91 & 15.62 & 7.76 & 5374.00 & $479,766.70$ & 0.43 & $<0.01$ & 7.69 & 454.00 & 3471.33 & $<0.01$ \\
\hline \multicolumn{12}{|l|}{ Uttar Pradesh } \\
\hline Obesity & 27.22 & 23.35 & 10.95 & 7875.00 & $517,199.70$ & 0.59 & $<0.01$ & 10.93 & 680.00 & 3858.00 & $<0.01$ \\
\hline Asthma & 29.02 & 24.25 & 11.18 & 8060.00 & $519,598.70$ & 0.60 & $<0.01$ & 10.81 & 675.00 & 3887.00 & $<0.01$ \\
\hline Hypertension & 36.72 & 26.27 & 11.04 & 8019.00 & $527,681.00$ & 0.58 & $<0.01$ & 11.10 & 700.00 & 3963.33 & $<0.01$ \\
\hline Fibrosis & 19.716 & 17.80 & 9.42 & 6745.00 & $512,483.00$ & 0.51 & $<0.01$ & 9.17 & 567.00 & 3808.33 & $<0.01$ \\
\hline \multicolumn{12}{|l|}{ West Bengal } \\
\hline Obesity & 26.64 & 22.68 & 11.63 & 8353.00 & $515,411.70$ & 0.63 & $<0.01$ & 11.35 & 703.00 & 3825.00 & $<0.01$ \\
\hline Asthma & 30.19 & 23.78 & 11.19 & 8070.00 & $520,314.70$ & 0.60 & $<0.01$ & 10.88 & 679.00 & 3881.67 & $<0.01$ \\
\hline Hypertension & 36.60 & 26.74 & 12.17 & 8845.00 & $528,004.30$ & 0.64 & $<0.01$ & 11.79 & 742.00 & 3951.33 & $<0.01$ \\
\hline Fibrosis & 20.08 & 18.67 & 9.57 & 6843.00 & $511,433.00$ & 0.52 & $<0.01$ & 9.06 & 559.00 & 3796.33 & $<0.01$ \\
\hline
\end{tabular}

stdev Standard deviation, $z$ Mann-Kendall statistics, S (Positive differences- Negative differences), varS Variance of S 
Table 4 Zone wise weekly RSV (with benchmark) for SCLD from 2004 to 2017

\begin{tabular}{lll}
\hline & Mean & Stdev \\
\hline Jammu Kashmir & & \\
Obesity & 0.79 & 6.47 \\
Asthma & 0.08 & 0.33 \\
Hypertension & 0.11 & 0.39 \\
Fibrosis & 0.60 & 7.69 \\
Rajasthan & & \\
Obesity & 4.73 & 9.86 \\
Asthma & 6.38 & 12.58 \\
Hypertension & 7.77 & 15.24 \\
Fibrosis & 3.06 & 8.16 \\
Uttar Pradesh & & \\
Obesity & 4.67 & 7.65 \\
Asthma & 6.30 & 8.81 \\
Hypertension & 7.96 & 12.92 \\
Fibrosis & 3.25 & 6.73 \\
West Bengal & & \\
Obesity & 3.87 & 8.23 \\
Asthma & 8.68 & 14.46 \\
Hypertension & 7.52 & 7.91 \\
Fibrosis & 2.76 & \\
\hline Std Standard & &
\end{tabular}

stdev Standard deviation, $z$ Mann-Kendall statistics, S (Positive differencesNegative differences), varS Variance of S

on SCLD activity in the context of chronotherapy is underutilized and could be a major consideration to improve modern personalized medicine [43-47]. Our GT study also identified highly significant comorbid seasonal rhythm of periodicity of 3,4 and 6 months in SCLD especially for asthma, obesity, fibrosis in the entire India. These seasonal rhythmic patterns could be readily exploited to estimate seasonality in SCLD to synchronize drug concentrations for better efficacy.

\section{Effect of temperature zones on SCLD}

The zone wise GT data allowed us to validate the significant seasonal rhythmic patterns of SCLD in different temperature zones. Several clinical studies established significant relationship between seasonal change in life style diseases and temperature [48-53]. Seasonal trends from a wide range of weather conditions across a vast geographic scale and varied topography. For example, the seasonal changes in Indian states belong to northern, central, north-east and southern regions are highly distinct and drastic. Considering the fact, we studied the effect of different climatic zones on the SCLD seasonality to validate our results. Interestingly, as expected similar significant seasonal patterns and positive trends were noticed in all the four temperature zones. These results indicate that significant seasonal search patterns in SCLD is conserved in India even in the case of drastic climatic regions. Yet the conservation of comorbid seasonal search patterns among SCLD in different Indian climatic zones have to be established.

\section{Limitations}

This study has several limitations in the text mining as well as electronic search (GT) that needs to be considered while interpreting the results. Most importantly, the individual performing the search is not necessarily suffering from the diseases. To validate our predictions, they should be correlated with clinical data. Meanwhile, the demographic characteristics were not available for the users who were performing the search. In addition, the seasonal patterns were not studied using any language other than English and with a search engine other than Google. Finally, the important caveat is only SCLD diseases terms used for GT analysis to study the effect on Indian population. In addition, the search behaviors of the individuals about the SCLD could not be assessed. According to the sources, around $74 \%$ of the internet user base will be comprised of internet users under 35 years old in 2016 [54].

\section{Conclusions}

The clinical outcome arise out of these predictions could be immense significance in handling the major chronic life style diseases asthma, hypertension, obesity and fibrosis. The possible strong comorbid relationship among hypertension, obesity and fibrosis may be useful to classify Indian seasonal sensitive population. As this disease population could be highly subject to the adverse effect of seasons in addition to life style and other environmental factors. Our study necessitates that these population needs special attention from the Indian health care sectors.

\section{Abbreviations \\ GT: Google trends; RSV: Relative search volume; SCLD: Seasonal sensitive comorbid lifestyle disease}

\section{Acknowledgements}

Not Applicable.

\section{Authors' contributions}

RS and JCP conceptualized, data collected/analysed, result visualized and drafted the manuscript for this study. PK, YKS and BK revised the paper. All authors have read and approved the final manuscript.

Funding

There is no funding source for this research work.

Availability of data and materials

The datasets used and/or analysed during the current study are available from the corresponding author on reasonable request.

Ethics approval and consent to participate Not Applicable. 


\section{Consent for publication}

Not Applicable.

\section{Competing interests}

The authors declare that they have no competing interests.

Received: 29 March 2019 Accepted: 24 February 2020

Published online: 12 March 2020

\section{References}

1. Thakkar J, Chaudhari S, Sarkar PK. Ritucharya: answer to the lifestyle disorders. Ayu. 2011;32(4):466-71.

2. Chandola HM. Lifestyle disorders: Ayurveda with lots of potential for prevention. Ayu. 2012:33(3):327.

3. Alter JS, Nair RM, Nair R. Nature Cure and Non-Communicable Diseases: Ecological Therapy as Health Care in India. Int J Environ Res Public Health. 2017;14(12):1525.

4. Martin LJ, Lee BE, Yasui Y. Google flu trends in Canada: a comparison of digital disease surveillance data with physician consultations and respiratory virus surveillance data, 2010-2014. Epidemiol Infect. 2016;144(2):325-32.

5. Tkachenko N, Chotvijit S, Gupta N, Bradley E, Gilks C, Guo W, Crosby H, Shore E, Thiarai M, Procter R, et al. Google trends can improve surveillance of type 2 diabetes. Sci Rep. 2017;7(1):4993.

6. Cervellin G, Comelli I, Lippi G. Is Google trends a reliable tool for digital epidemiology? Insights from different clinical settings. J Epidemiol Global Health. 2017;7(3):185-9.

7. Verma M, Kishore K, Kumar M, Sondh AR, Aggarwal G, Kathirvel S. Google search trends predicting disease outbreaks: an Analysis from India. Healthc Inform Res. 2018;24(4):300-8.

8. Patel JC, Khurana P, Sharma YK, Kumar B, Ragumani S. Chronic lifestyle diseases display seasonal sensitive comorbid trend in human population evidence from Google trends. PLoS One. 2018;13(12):e0207359.

9. Jiang SZ, Lu W, Zong XF, Ruan HY, Liu Y. Obesity and hypertension. Exp Ther Med. 2016;12(4):2395-9.

10. Re RN. Obesity-related hypertension. Ochsner J. 2009;9(3):133-6.

11. Christiansen SC, Schatz M, Yang SJ, Ngor E, Chen W, Zuraw BL. Hypertension and asthma: a comorbid relationship. J Allergy Clin Immunol Pract. 2016;4(1):76-81.

12. Khaodhiar L, McCowen KC, Blackburn GL. Obesity and its comorbid conditions. Clin Cornerstone. 1999;2(3):17-31.

13. Peters U, Dixon AE, Forno E. Obesity and asthma. J Allergy Clin Immunol. 2018;141(4):1169-79.

14. Carpaij OA, van den Berge $M$. The asthma-obesity relationship: underlying mechanisms and treatment implications. Curr Opin Pulm Med. 2018;24(1):42-9.

15. Diez J. Mechanisms of cardiac fibrosis in hypertension. J Clin Hypertens. 2007;9(7):546-50.

16. Boutayeb A, Boutayeb S. The burden of non communicable diseases in developing countries. Int J Equity Health. 2005;4(1):2.

17. Majra JP, Gur A. Climate change and health: why should India be concerned? Indian J Occup Environ Med. 2009;13(1):11-6.

18. Burt T, Sharma P, Dhillon S, Manchanda M, Mittal S, Trehan N. Clinical research environment in India: challenges and proposed solutions. J Clin Res Bioethics. 2014;5(6):1-8.

19. Pappachan MJ. Increasing prevalence of lifestyle diseases: high time for action. Indian J Med Res. 2011;134:143-5.

20. Sidhu S, Kaur A, Prabhjot. Prevalence of overweight and obesity among urban and rural adult females of Punjab. Anthropologischer Anzeiger; Bericht uber die biologisch-anthropologische Literatur. 2005;63(3):341-5.

21. Sood RK, Gupta AK, Ahluwalia SK, Dhadwal D, Sharma RK. An epidemiological study of obesity in Shimla town. Indian J Med Sci. 1996; 50(10):362-4.

22. Ho JY. Early-life environmental exposures and height, hypertension, and cardiovascular risk factors among older adults in India. Biodemography and Social Biol. 2015;61(2):121-46.

23. Goyal A, Aslam N, Kaur S, Soni RK, Midha V, Chaudhary A, Dhaliwal LK, Singh B, Chhabra ST, Mohan B, et al. Factors affecting seasonal changes in blood pressure in North India: a population based four-seasons study. Indian Heart J. 2018;70(3):360-7.

24. Anuradha RK, Sathyavathi RB, Reddy TM, Hemalatha R, Sudhakar G, Geetha $P$, Reddy KK. Effect of social and environmental determinants on overweight and obesity prevalence among adolescent school children. Indian J Endocrinol Metab. 2015;19(2):283-7.

25. Ranjani H, Mehreen TS, Pradeepa R, Anjana RM, Garg R, Anand K, Mohan V. Epidemiology of childhood overweight \& obesity in India: a systematic review. Indian J Med Res. 2016;143(2):160-74.

26. D'Amato G, Holgate ST, Pawankar R, Ledford DK, Cecchi L, Al-Ahmad M, AlEnezi F, Al-Muhsen S, Ansotegui I, Baena-Cagnani CE, et al. Meteorological conditions, climate change, new emerging factors, and asthma and related allergic disorders. A statement of the World Allergy Organization. World Allergy Organ J. 2015;8(1):25.

27. Collaco JM, McGready J, Green DM, Naughton KM, Watson CP, Shields T, Bell SC, Wainwright CE, Group AS, Cutting GR. Effect of temperature on cystic fibrosis lung disease and infections: a replicated cohort study. PLoS One. 2011;6(11):e27784.

28. PKD IK. Intercomparability of isotropic and anisotropic solar radiation models for different climatic zones of India. Environ Prog Sustain Energy. 2013;33(3):925-32

29. Hasnain N. Indian society and culture: continuity and change. New Royal Book Company; 2010.

30. Basu A, Mukherjee N, Roy S, Sengupta S, Banerjee S, Chakraborty M, Dey B, Roy M, Roy B, Bhattacharyya NP, et al. Ethnic India: a genomic view, with special reference to peopling and structure. Genome Res. 2003;13(10):2277-90.

31. https://www.india.gov.in/india-glance/states-india. 2018.

32. Pohlert T. Trend: non-parametric trend tests and change-point detection. $R$ package version 111; 2018

33. Team RC: $R$ : a language and environment for statistical computing. $R$ Foundation for Statistical Computing 2018.

34. Hyndman YK RJ. Automatic Time Series Forecasting: The forecast Package for R. J Stat Softw. 2008;26:1-22.

35. Kumar P, Ram U. Patterns, factors associated and morbidity burden of asthma in India. PLoS One. 2017;12(10):e0185938.

36. Gupta R, Gaur K, CV SR. Emerging trends in hypertension epidemiology in India. J Hum Hypertens. 2019;33(8):575-87.

37. Ahirwar R, Mondal PR. Prevalence of obesity in India: a systematic review. Diabetes Metab Syndr. 2019;13(1):318-21.

38. India State-Level Disease Burden Initiative CRDC. The burden of chronic respiratory diseases and their heterogeneity across the states of India: the global burden of disease study 1990-2016. Lancet Glob Health. 2018;6(12): e1363-74.

39. Ballesta A, Innominato PF, Dallmann R, Rand DA, Levi FA. Systems Chronotherapeutics. Pharmacol Rev. 2017;69(2):161-99.

40. Roenneberg T, Merrow M. The circadian clock and human health. Current Biol. 2016;26(10):R432-43.

41. Xie Y, Tang Q, Chen G, Xie M, Yu S, Zhao J, Chen L. New insights into the circadian rhythm and its related diseases. Front Physiol. 2019;10:682.

42. Honma K, Honma S, Kohsaka M, Fukuda N. Seasonal variation in the human circadian rhythm: dissociation between sleep and temperature rhythm. Am J Phys. 1992;262(5 Pt 2):R885-91.

43. Burioka N, Sasaki T. Chronopharmacology and chronotherapy for asthma by using PEF. Nihon rinsho Japanese journal of clinical medicine. 1996;54(11): 2956-61.

44. Di Vincenzo M, Guagnano MT, Della Loggia F, Sensi S. Chronotherapy of obesity. II. Variations in eating behavior in the obese after fenfluramine treatment in relation to time of administration. Bollettino della Societa italiana di biologia sperimentale. 1982:58(12):740-4.

45. Guagnano MT, Di Vincenzo M, Sensi S. Chronotherapy of obesity. I. Effect of fenfluramine on the decrease of adipose mass in the obese, in relation to the time of administration. Bollettino della Societa italiana di biologia sperimentale. 1982;58(12):736-9.

46. Bowles NP, Thosar SS, Herzig MX, Shea SA. Chronotherapy for hypertension. Curr Hypertens Rep. 2018;20(11):97.

47. Pekovic-Vaughan V, Gibbs J, Yoshitane H, Yang N, Pathiranage D, Guo B, Sagami A, Taguchi K, Bechtold D, Loudon A, et al. The circadian clock regulates rhythmic activation of the NRF2/glutathione-mediated antioxidant defense pathway to modulate pulmonary fibrosis. Genes Dev. 2014;28(6): 548-60.

48. Fares A. Winter hypertension: potential mechanisms. Int J Health Sci. 2013 7(2):210-9.

49. Barnett AG, Sans S, Salomaa V, Kuulasmaa K, Dobson AJ, Project WM. The effect of temperature on systolic blood pressure. Blood Press Monit. 2007; 12(3):195-203. 
50. Bastardot F, Marques-Vidal P, Vollenweider P. Association of body temperature with obesity. The CoLaus study. Int J Obes. 2019;43(5):1026-33.

51. Yang HK, Han K, Cho JH, Yoon KH, Cha BY, Lee SH. Ambient temperature and prevalence of obesity: a Nationwide population-based study in Korea. PLoS One. 2015;10(11):e0141724.

52. Cong $X, X u X$, Zhang $Y$, Wang $Q, X u L$, Huo $X$. Temperature drop and the risk of asthma: a systematic review and meta-analysis. Environ Sci Pollut Res Int. 2017;24(28):22535-46.

53. Xu Z, Crooks JL, Davies JM, Khan AF, Hu W, Tong S. The association between ambient temperature and childhood asthma: a systematic review. Int J Biometeorol. 2018;62(3):471-81.

54. Tapashi D. A Study on Aspects of India's Digital Divide. RESEARCH REVIEW International Journal of Multidisciplinary November. 2018;3(11):689-93.

\section{Publisher's Note}

Springer Nature remains neutral with regard to jurisdictional claims in published maps and institutional affiliations.

Ready to submit your research? Choose BMC and benefit from:

- fast, convenient online submission

- thorough peer review by experienced researchers in your field

- rapid publication on acceptance

- support for research data, including large and complex data types

- gold Open Access which fosters wider collaboration and increased citations

- maximum visibility for your research: over $100 \mathrm{M}$ website views per year

At $\mathrm{BMC}$, research is always in progress.

Learn more biomedcentral.com/submissions 